\title{
Apresentação
}

\section{Conhecimentos e redes: produção e apropriação de C\&T}

MÁRA BAUMGARTEN

NAN DA COSTA MARQUES

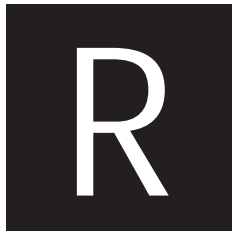

eestruturações econômicas, organizacionais e culturais na configuração das sociedades contemporâneas colocam grandes desafios para as Ciências Sociais. $\mathrm{Na}$ emergência de novas formas naturais e societárias que caracterizam o que alguns denominam "sociedade de informação" e outros chamam "sociedade do conhecimento" ou "do aprendizado", as questões do "saber sobre o saber" se posicionam em um plano crucial para as análises da produção/distribuição do saber (informação e conhecimento) e das possibilidades de redução das desigualdades sociais. 0 "saber sobre 0 saber" desempenha, atualmente, papel estratégico, não só para a acumula-

\footnotetext{
* Drª em Sociologia. Professora do Departamento de Educação e Ciências do Comportamento da U niversidade Federal de Rio Grande e do Programa de Pós-graduação em Sociologia da UFRGS e coordenadora do Centro de Estudose Difusão de Conhecimentos, Inovação e Sustentabilidade CEDCIS (www.ufrgs.br/cedcis).

** Ph.D. em Engenharia Elétrica e Ciência da Computação. Pós-doutorado em história e sociologia das ciências e das tecnologias. Professor Associado do Programa de Pós-Graduação em Informática do NCE-IM/U FRJ e do Programa de Pós-Graduação em História das Ciências e das Técnicas e Epistemologia da UFRJ. Agradeço ao NCE/UFRJ o apoio às minhas atividades no campo dos Estudos CTS, sem o qual minha participação nesta edição não teria sido possível.
} 
ção econômica, mas também para o funcionamento do próprio Estado e da sociedade (Stehr, 1994; Lastrese Albagli, 1999; Maciel, 2001).

As mudanças que acompanham a formação de coletivos crescentemente mundializados desde a segunda metade do século XX e os concomitantes agud os desenvolvimentos das tecnologias de informação e de comunicação são, ao mesmo tempo, objetos de estudo das chamadas ciências sociais e elementos estratégicos na transformação das condições destes coletivos produzirem informação e conhecimentos. Ao serem indissociáveis como objetos de estudo e elementos de transformação, estes processos viabilizam diferentes possibilidades de registro e de acompanhamento das relações entre atores, alteram significativamente as fontes e formas de geração de indicadores e facilitam a formação de redes.

Em outras palavras, a importância das redes de produção, disseminação e apropriação de conhecimentos tornou estratégica a reflexão sobre as mesmas e sobre as possibilidades e repercussões que trazem para as formas da vida econômica, social e cultural, notadamente para as possibilidades de atividades inter e trans-disciplinares e setoriais.

0 dossiê desse número de Sociologias abre com o artigo do pesquisador canadense Arnaud Sales, denominado Criatividade, comunicação e produção do saber. Ao colocar em debate o papel dos indivíduos, das redes intelectuais e científicas, da coletividade dos pares e das instituições o autor sustenta que a idéia de criatividade reflexiva, própria às nossas sociedades, não pode ser pensada de maneira determinista e independentemente da interação permanente dos indivíduos em redes e instituições. Sales parte de algumas questões com o objetivo de apreender, de um ponto de vista sociológico, diversas facetas da relação entre criatividade, comunicação e produção do conhecimento: "como situar o papel da comunicação na elaboração de descobertas ou nos avanços intelectuais? Q uais são os papéis do indivíduo e das redes nesses avanços? Q uais são, enfim, os traços especialmente comunicacionais das instituições mais criativas?" 
De acordo com Sales, as grandes infra-estruturas implantadas no âmbito de políticas da pesquisa são, sem dúvida alguma, muito úteis, senão indispensáveis, mas só podem levar a descobertas, inovações ou à definição de novas problemáticas se as comunicações entre os pesquisadores de diferentes disciplinas se estabelecem com regularidade, liberdade e densidade.

O s artigos de Cristina H olmes, Cory Hayden, Henrique Cukierman e Márcia Teixeira abordam o fazer científico e elementos de sua apropriação social na América-Latina e no Brasil.

Christina Holmes, que concluiu em 2007 um Ph.D. interdisciplinar na U niversidade Dalhouse em H alifax, Canadá, pesquisando as questões sociais em torno à engenharia genética de plantas, adota uma abordagem etnográfica em trabalhos de campo no Canadá e na Colômbia para explorar os papéis da engenharia genética na pesquisa realizada junto a agricultores e cientistas.

Em “O fascínio dos cientistas colombianos pela engenharia genética de plantas" a autora analisa o campo da biotecnologia e a engenharia genética de plantas na Colômbia. Segundo H olmes, biotecnologia e engenharia genética de plantas têm forte apelo na Colômbia, devido ao potencial que essa tecnologia proporciona para participar da nova economia do conhecimento e também como uma forma de explorar a grande biodiversidade do país. Contudo, a tecnologia de engenharia genética e a produção de conhecimento resultante são dominadas por interesses e recursos do hemisfério norte. Cientistas colombianos que fazem uso da engenharia genética devem trabalhar dentro desse contexto. Ainda assim, muitos acreditam que seus projetos de pesquisa beneficiarão à Colômbia. Essa tecnologia, portanto, oscila entre o otimismo quanto ao seu futuro em potencial e as barreiras impostas pelas condições globais em que ocorre.

Cori Hayden, professora associada do Departamento de Antropologia da Universidade da Califórnia, Berkeley, tem estudado como as proposições relativas ao material e conhecimento biológico atuam na conformação do imaginário social contemporâneo de participação e marginalização. 
H ayden está interessada nas relações entre comunidades 'locais', cientistas do setor público e laboratórios farmacêuticos envolvidos em "acordos controvertidos de compartilhamento de benefícios" e também em abordagens críticas, de base etnográfica, dos regimes de propriedade intelectual, ética e outras formas de governança.

A partir destas temáticas Cori Hayden nos apresenta um trabalho baseado em pesquisas etnográficas no M éxico e na Argentina, denominado "Sem patente não há genérico: acesso farmacêutico e políticas de cópia". A autora avalia as promessas, limites e especificidades do medicamento genérico como artefato político, técnico e legal. Hayden procura mostrar que “o que está em jogo com a expansão dos mercados para medicamentos genéricos não é simplesmente uma relação do tipo David e Golias entre o genérico (barato, acessível, democratizante) e o original patenteado (caro)". Também central para uma política do genérico, segundo Hayden, é "a linha de deslocamento entre a cópia lícita e ilícita".

Henrique Luiz Cukierman e Márcia de O liveira Teixeira tratam do diaa-dia do Instituto de M anguinhos (Rio de Janeiro, Brasil) nas primeiras décadas do século 20, destacando as relações de trabalho no interior dos laboratórios. Segundo os autores, aquele cotidiano revela que, apesar de sua pequenez, o quadro técnico-científico da época derivava sua extraordinária produtividade da diversidade de suas atividades. Tratava-se de pessoal dotado de excepcional flexibilidade tanto na ação quanto na eleição de seu objeto de estudo. Cukierman e Teixeira levantam a hipótese de que tamanha flexibilidade relaciona-se à compreensão da ciência local como parte das práticas culturais locais. Seguindo a trilha aberta pelo conceito de homem cordial, conforme definido por Sergio Buarque de Holanda em seu Raízes do Brasil, os autores indagam se existiria em M anguinhos a ciência cordial. 0 artigo oferece algumas possibilidades de resposta a partir do exame das relações que se estabeleceram entre os cientistas e seus 'subalternos', os ajudantes de pesquisa, nas quais o rigor e o formalismo das 
práticas científicas de laboratório conviveram com relações patriarcais tipicamente brasileiras.

Em um outro bloco temático são apresentados debates sobre desafios éticos envolvidos na produção da tecnociência e questões relacionadas à privatização do conhecimento.

Amaro e Almeida empreendem um debate sobre "Tecnociência, democracia e os desafios éticos das biotecnologias no Brasil". O s autores abordam diferentes tendências que tratam do tema. De acordo com Amaro e Almeida, as discussões envolvendo as novas biotecnologias, em nível mundial e no Brasil, são reveladoras de características interessantes deste novo momento da humanidade. Em sua análise, os pontos de acesso desencadeados por pavoresalimentarese preocupaçõesambientais provocam reordenamentos de implicações éticas, sociais e políticas. A principal questão sobre a qual o texto se propõe a refletir é: "Como tais reordenamentos sinalizam para novas tendências no processo de gestão das tecnologias à luz da recente polêmica configurada em torno das novas biotecnologias no Brasi?"

Em "Capital social e a privatização do conhecimento" Renato P. Saul examina o movimento intelectual que envolveu a reflexão científica nas ciências sociais a partir dos anos 1960 e suas vinculações com as transformações que, na mesma época, agitavam as relações econômicas e políticas no plano mundial, com seu foco principal apontado para os Estados U nidos. De acordo com Saul, esse é o contexto em que a noção de capital social adquire o sentido de articulador principal das disputas políticas e teóricas em torno do desenvolvimento econômico e das transformações verificadas na atividade industrial resultantes da expansão de novas tecnologias e de seus efeitos em termos da necessidade de redimensionamento do direito de propriedade intelectual.

Nosso objetivo com esse dossiê foi trazer um conjunto de questões que giram ao redor da temática das redes e do "saber sobre o saber" que, a nosso ver, assume importância crescente, notadamente para países da 
América Latina, onde as políticas do saber se dão em meio a altos níveis de exclusão. Essa temática remete à relação entre produção de ciência, tecnologia, inovações e condições de vida e à necessidade da ampliação do debate social em torno da tecnociência, sua construção e usos e as possibilidades de inclusão de novos atores nesse debate.

Na contemporaneidade o "saber sobre o saber" confere importância à criação e à apropriação de conhecimentos tecnocientíficos capazes de gerar inovações e satisfazer as demandas que vêm se configurando em decorrências do fortalecimento dasformas democráticas na região.

Inclusão social, econômica e política vinculam-se, fortemente, ao saber sobre o saber da ciência e da tecnologia e ao incremento da capacidade de crítica, na sociedade, sobre os processos de produção e apropriação de ciência e tecnologia (Maciel, 2005). A ampliação do debate público sobre os processos de construção do saber é essencial para tornar visíveis mediações que mesclam indissociavelmente as instâncias produtoras de CT\&I e a sociedade e, também, para construir novas mediações articuladas à nossa realidade.

\section{Referências}

LASTRES, H. M. M.; ALBAGLI, S. (O rgs.). Informação e globalização na era do conhecimento. Rio de Janeiro: Campus, 1999.

MACIEL, M.L "Hélices, Sistemas, Ambientes e Modelos: Os Desafios Teóricos à Sociologia de C\&T". Sociologias, n. 6, Porto Alegre, PPGS/U niversidade Federal do Rio Grande do Sul, 2001.

MACIEL, M. "Estímulos e desestímulos à divulgação do conhecimento científico". In: BAUMGARTEN, M (org.). Conhecimentos e redes - sociedade, política e inovação. Porto Alegre: Ed. U niversidade/UFRGS, 2005.

STEHR, N. Knowledge Societies. Londres, Sage, 1994. 
Sociologias, Porto Alegre, ano 10, no 19, jan./jun. 2008, p. 14-21

\section{Resumo}

As mudanças que acompanham a formação de coletivos crescentemente mundializados e os concomitantes desenvolvimentos das tecnologias de informação e de comunicação são elementos estratégicos na transformação das condições destes coletivos produzirem informação e conhecimentos. A importância das redes de produção, disseminação e apropriação de conhecimentos tornou estratégica a reflexão sobre as mesmas e sobre as possibilidades e repercussões que trazem para as formas da vida econômica, social e cultural, notadamente para as possibilidades de atividades inter e trans-disciplinares e setoriais. Nosso objetivo, aqui, é apresentar um conjunto de debates sobre essa temática, que remete à relação entre produção de ciência, tecnologia, inovações e condições de vida e à necessidade da ampliação do debate social em torno da tecnociência, sua construção e usos e as possibilidades de inclusão de novos atores nesse debate.

Palavras-chave: ciência e tecnologia, redes, produção de ciência, apropriação de ciência e tecnologia 


\section{Knowledge and Networks: production and appropriation of science and technology}

\section{Maíra Baumgarten e Ivan da Costa Marques}

The changes that accompany the formation of increasingly globalized collectives and the concomitant development of information and communication technologies are strategic elements in the transformation of these collectives' conditions to produce knowledge and information. Due to the importance given to the networks of knowledge production, dissemination and appropriation, it has become strategic to consider those networks, as well as the possibilities and implications that they bring to the forms of economic, social and cultural life, especially to the possibilities of interdisciplinary, transdisciplinary and sectorial activities. The purpose here is to present a series of debates on this subject, which refers to the relationship between the production of science, technology, innovation and living conditions, and the need for an extension of the social debate on technoscience, its construction, uses, and the possibilities for the inclusion of new actors in this debate.

Keywords: science and technology, networks, science production, appropriation of science and technology. 